\title{
Comparable Effect of Two-Step Versus Extended Infusions on the Pharmacokinetics of Imipenem in Patients with Sepsis and Septic Shock
}

\author{
Yingzi Huang $\cdot$ Kang Xu $\cdot$ Ying Zhan · Xian Zha · Songqiao Liu • \\ Jianfeng Xie $\cdot$ Lin Liu $\cdot$ Qing Li · Hua Shao · Yi Yang
}

Received: August 19, 2019 / Published online: April 10, 2020

(c) Springer Healthcare Ltd., part of Springer Nature 2020

\section{ABSTRACT}

Introduction: The present study aimed to compare the pharmacokinetic/pharmacodynamic (PK/PD) parameters of imipenem administered by two-step (50\% delivered in a 30 -min bolus, $50 \%$ for the following $90 \mathrm{~min}$ ) or extended (administered continuously for $2 \mathrm{~h}$ ) infusion.

Methods: Patients with sepsis and septic shock were prospectively enrolled and randomized into four groups. Subjects in the two-step or

Enhanced Digital Features To view enhanced digital features for this article go to https://doi.org/10.6084/ m9.figshare.11591781.

Electronic supplementary material The online version of this article (https://doi.org/10.1007/s12325020-01339-5) contains supplementary material, which is available to authorized users.

Y. Huang $\cdot$ S. Liu $\cdot$ J. Xie $\cdot$ L. Liu $\cdot$ Q. Li .

Y. Yang $(\bowtie)$

Department of Critical Care Medicine, Zhongda

Hospital, School of Medicine, Southeast University,

Nanjing, China

e-mail: yiyiyang2004@163.com

K. Xu

Pharmacy Department, Hospital for Skin Diseases, Chinese Academy of Medical Sciences, Nanjing, China

Y. Zhan $\cdot$ X. Zha $\cdot$ H. Shao

Pharmacy Department, Zhongda Hospital, School of Medicine, Southeast University, Nanjing, China extended groups were given two doses of imipenem $(0.5 \mathrm{~g} q 6 \mathrm{~h}$ and $1.0 \mathrm{~g} q 8 \mathrm{~h})$. The plasma imipenem concentrations were measured at given time points after the fifth dose. The PK/ PD target was defined as the achievement of a fractional time above the minimal inhibitory concentration (MIC) of $>40 \%$.

Results: Thirty-five patients were eventually enrolled. No significant difference was observed in the percentage of patients achieving $40 \%$ $T>$ MIC between the different infusion modes with the same dosage, although the two-step groups exhibited a significantly shorter $T_{\max }$ compared with the extended groups $(0.5 \mathrm{~g} q 6 \mathrm{~h}$ : $1.5 \pm 0.8$ vs. $2.0 \pm 0.0 \mathrm{~h} ; 1.0 \mathrm{~g} q 8 \mathrm{~h}: 1.0 \pm 0.6$ vs. $2.0 \pm 0.0 \mathrm{~h}$; both, $p<0.05)$. All four groups achieved $40 \% \quad T>$ MIC when MIC was $0.5-4.0 \mu \mathrm{g} / \mathrm{ml}$, but only regimens with a higher dose (1.0 g q8h) achieved target when MIC was $8 \mu \mathrm{g} / \mathrm{ml}$.

Conclusion: The two-step and extended regimens of imipenem are comparable to the PK/PD target in the treatment of sepsis and septic shock. A higher dose $(1.0 \mathrm{~g} q 8 h)$ should be considered for target achievement at an MIC of $>8 \mu \mathrm{g} / \mathrm{ml}$.

Trial Registration: ClinicalTrials.gov identifier, NCT02616354.

Keywords: Imipenem; Infectious disease; Infusion mode; Minimal inhibitory concentration; Pharmacokinetic/ pharmacodynamic; Sepsis 


\section{Key Summary Points}

The present study is an exploratory prospective study that attempted to address a practical question: whether the efficacy of imipenem could be improved by the two-step infusion mode instead of the traditional extended infusion mode.

The differences in PK/PD parameters of imipenem between the two infusion modes were investigated in patients with sepsis and septic shock.

To our knowledge, these results are the first to confirm that both infusion modes are comparable in terms of the PK/PD target in the treatment of sepsis and septic shock.

\section{INTRODUCTION}

Sepsis and septic shock are life-threatening conditions with high morbidity and mortality $[1,2]$. A prompt initiation of sufficient, appropriate and empiric antibiotics is critical for the treatment of sepsis and septic shock [3, 4]. Imipenem, a carbapenem antibiotic, is one of the most important antibiotics used to cover of a wide spectrum of pathogens, including grampositive, gram-negative, aerobic, anaerobic and multidrug-resistant strains [5]. Imipenem exhibits time-dependent bactericidal activity, and the pharmacokinetic/pharmacodynamic (PK/ $\mathrm{PD})$ parameter that best predicts in vivo antimicrobial activity is $\% T>$ minimal inhibitory concentration (MIC), defined as the percentage of time during which the plasma concentration remains above the minimum inhibitory concentration of pathogens $[6,7]$. However, in the clinical setting of sepsis and septic shock, not only substantial pathophysical changes, but also different infusion regimens significantly alter the antimicrobial PK/PD index $[8,9]$. Thus, this may affect clinical outcome. Hence, the 2016 Surviving Sepsis
Campaign (SSC) guidelines reinforced that antibiotic regimens should be optimized based on the PK/PD principle in patients with sepsis and septic shock [2].

The optimal infusion regimen of imipenem in patients with sepsis and septic shock remains undetermined. Early studies in healthy volunteers have demonstrated that carbapenems administered by continuous infusion improved the blood concentrations above MIC compared with intermittent infusion regimens [10]. In critical patients with ventilator-associated pneumonia (VAP), continuous infusion was correlated with better clinical efficacy compared with intermittent infusion [11]. However, the practical application of carbapenems in continuous infusion mode remains challenging because of its inherent stability issue [12]. A 3-h infusion, instead of continuous infusion, was thereby developed because of its feasibility and superiority [13]. Evidence has revealed that the 3-h infusion results in greater $T>$ MICs than those after a bolus injection in patients with VAP [13]. A 3-h infusion of imipenem may improve the cumulative probability of target attainment (PTA) for various microorganisms compared with a 30-min infusion [14]. Recently, with the use of an in vitro pharmacodynamic model and the Monte Carlo simulation, the optimized two-step infusion therapy (rapid first-step infusion and slow second-step infusion) of meropenem has been proven to have better initial bactericidal effects than a prolonged infusion therapy due to the sufficient $\% T>$ MIC and $C_{\max }$, with a shorter $T_{\max }$ [15]. However, whether the two-step infusion regimen of imipenem elicits a greater $T>$ MIC than the conventional extended infusion method, especially in critical patients, is still unknown.

The present exploratory study evaluated the PK/PD changes of the two-step vs. extended infusion of imipenem for treating sepsis and septic shock due to various pathogens. The $\% T>$ MIC and other pharmacokinetic indices were compared in both regimens, with a dose of $0.5 \mathrm{~g} q 6 \mathrm{~h}$ and $1.0 \mathrm{~g} q 8 \mathrm{~h}$. 


\section{METHODS}

\section{Patients and Materials}

This single-institution, prospective, randomized comparative study was performed in the Intensive Care Unit (ICU), Zhongda Hospital, School of Medicine, Southeast University, Nanjing, China. The protocol was approved by the Ethics Committee of Zhongda Hospital. Written informed consent was obtained from all patients or their legal guardians. The present study was in compliance with the American Clinical Trials Register (ClinicalTrials.gov) agreement (registration no. NCT02616354).

Inclusion criteria were: (1) patients with severe sepsis or septic shock diagnosed within $48 \mathrm{~h}$ of admission; (2) patients prescribed imipenem, as recommended by the hospital microbiologists who had a role as consultants to assess the antibiotic consumption; (3) patients with an expected ICU stay duration $\geq 72 \mathrm{~h}$. Sepsis/septic shock was defined according to the International Sepsis Definitions Conference and the updated sepsis $3.0[1,3]$.

Exclusion criteria were: patients who were $<18$ or $>75$ years old, patients who were allergic or had adverse effects to imipenem, cephalosprins, penicillins or other $\beta$-lactams, patients with acute or chronic renal failure defined as a serum creatinine concentration of $>280 \mu \mathrm{mol} / \mathrm{l} \quad$ (or a creatinine clearance of $<20 \mathrm{ml} / \mathrm{min}$ ), or requiring intermittent hemodialysis and continuous renal replacement therapy, patients with drug or alcohol abuse, patients with a susceptibility test revealing resistance or ineffectiveness to imipenem (such as viruses, fungi, etc.), patients who were pregnant and lactating, and patients who participated in other clinical trials.

Patient characteristics, including gender, age, weight, APACHE II score, liver and kidney function, and underlying diseases were collected on admission. The comorbidities, concomitant medications and risk factors (longterm use of corticosteroids, recent surgery, invasive mechanical ventilation, being immune compromised or using antimicrobial agents) were all recorded. Imipenem/cilastatin (Merck
Sharp \& Dohme B.V., Haarlem, Netherlands) was used for the present study.

\section{Study Design}

All eligible patients received either $0.5 \mathrm{~g} q 6 \mathrm{~h}$ or $1.0 \mathrm{~g} q 8 \mathrm{~h}$ of imipenem, as assessed by the type and severity of infection through a microbiology consultant. Then, these patients were randomized using the random permuted blocks method to receive either the two-step infusion or extended infusion regimen. In the two-step groups, 50\% imipenem dose was given with a bolus in $30 \mathrm{~min}$. Then, the remaining 50\% dose was administered for $90 \mathrm{~min}$. In the extended group, imipenem was administered within $120 \mathrm{~min}$. Each dose of imipenem was infused using a central venous catheter through a separate lumen. A microbiologist blinded to the patient allocation assessed the microbiologic outcomes after a 72-h period to determine whether it was necessary to de-escalate or adjust the antibiotics. The study flow is presented in Fig. 1.

The characteristics of all patients were collected, including the following: clinical and biochemical indicators, including age, gender, weight, Acute Physiology and Chronic Health Evaluation (APACHE) II score, Sequential Organ Failure Assessment (SOFA) score, blood urea nitrogen (BUN), creatinine (Cr), creatinine clearance (CLcr), albumin, alanine aminotranferease (ALT), aspartate aminotransferase (AST), total bilirubin (TB), white blood cell count (WBC), C-reactive protein (CRP), procalcitonin (PCT) and infection site (Table 1).

\section{Sampling and Imipenem Assay}

Blood samples $(2 \mathrm{ml})$ were collected after the fifth imipenem dose at $0,0.5,1.0,2.0,4.0$ and $6.0 \mathrm{~h}$ for the $0.5 \mathrm{~g} q 6 \mathrm{~h}$ groups and at $0,0.5,1.0$, 2.0, 4.0, 6.0 and $8.0 \mathrm{~h}$ for the $1.0 \mathrm{~g} q 8 \mathrm{~h}$ groups. Furthermore, urine samples were concurrently collected. The imipenem concentrations in plasma and urine were determined by highperformance liquid chromatography (HPLC) with ultraviolet (UV) detection. Briefly, $250 \mu \mathrm{l}$ of the plasma sample was added to $250 \mu \mathrm{l}$ of 


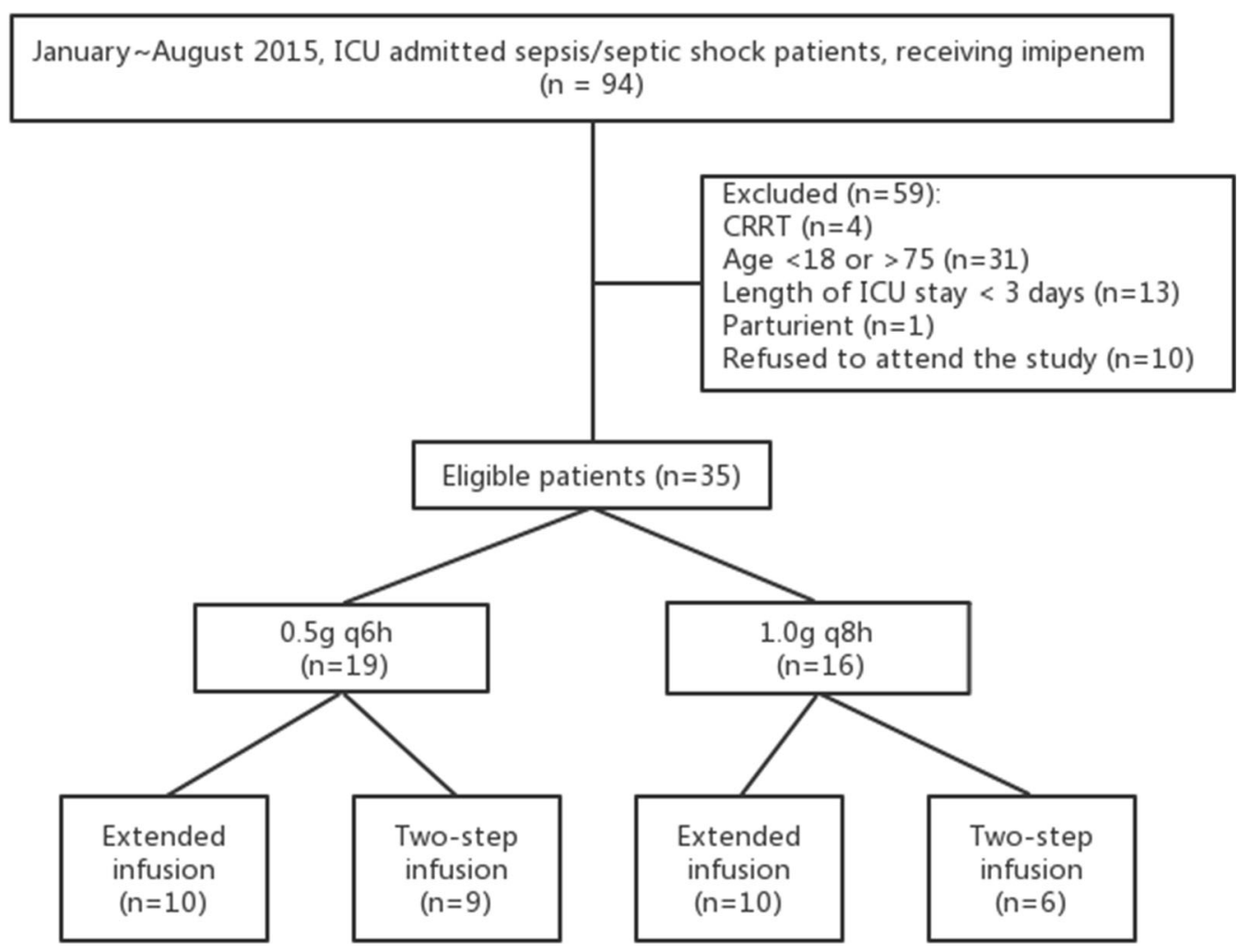

Fig. 1 Study flowchart

stabilizing solution and subjected to ultrafiltration for $10 \mathrm{~min}$ at $6000 \mathrm{~g}$. Then, the sample was injected with an automated system onto an Alltima HP Hilic Column $(4.6 \times 250 \mathrm{~mm}$, $5 \mu \mathrm{m})$, with acetonitrile $(10 \mathrm{mmol} / \mathrm{l})$-ammonium acetate $(2 \%)(60: 40)$ as the mobile phase. The flow rate was $1 \mathrm{ml} / \mathrm{min}$, and the column temperature was $35{ }^{\circ} \mathrm{C}$. The detector was operated at $298 \mathrm{~nm}[16,17]$. The lowest detectable concentration in plasma and urine was $0.02 \mathrm{mg} / \mathrm{l}$.

\section{Statistical and Pharmacokinetic Analysis}

Data were processed using Microsoft Excel (Microsoft Excel 2007, Microsoft Corp.). The pharmacokinetic parameters were calculated using the non-compartmental method, and the bioequivalence evaluation was performed using the BAPP 3.1 statistical software (China Pharmaceutical University, China). The imipenem plasma peak concentration $\left(C_{\max }\right)$, peak time $\left(T_{\max }\right)$, elimination of half-life $\left(T_{1 / 2}\right)$, imipenem clearance $(\mathrm{Cl})$, renal clearance $(\mathrm{Ccr})$, apparent distribution volume ( $\mathrm{Vd})$, area under the concentration-time curve $\left(\mathrm{AUC}_{0-t}\right)$ and area under the concentration from zero to the end of the dosing period $\left(\mathrm{AUC}_{0-\mathrm{tau}}\right)$ were calculated. $C_{\max }$ : the highest detection limit for each patient. $T_{\max }$ : time to reach $C_{\max } . T_{1 / 2}$ : the time required for the concentration of the drug to reach half of its original value. AUC: The integral of the concentration-time curve. The PK/PD target was defined as $\% T>$ MIC for $40 \%$ [18].

Data were expressed as mean \pm standard deviation (SD) or median (interquartilerange), as appropriate. Continuous variables were compared using one-way ANOVA test and $t$ test, and categorical data were analyzed using $X^{2}$ or Fisher's exact test. Data were analyzed using the SPSS 20.0 statistical software (SPSS Inc. Chicago, IL, USA). $p<0.05$ was considered statistically significant. 
Table 1 Baseline characteristics

\begin{tabular}{|c|c|c|c|c|}
\hline \multirow[t]{2}{*}{ Characteristics } & \multicolumn{2}{|l|}{ Two-step } & \multicolumn{2}{|l|}{ Extended } \\
\hline & $0.5 \mathrm{~g} q 6 \mathrm{~b}(n=9)$ & $1.0 \mathrm{~g} q 8 b(n=6)$ & $0.5 \mathrm{~g} q 6 b(n=10)$ & $1.0 \mathrm{~g} q 8 b(n=10)$ \\
\hline Age (years) & $59.4 \pm 16.7$ & $65.7 \pm 9.4$ & $68.1 \pm 11.4$ & $64.2 \pm 9.3$ \\
\hline Gender (male/female) & $8 / 1$ & $5 / 1$ & $9 / 1$ & $7 / 3$ \\
\hline Weight (kg) & $66.7 \pm 9.7$ & $70.8 \pm 7.4$ & $70.0 \pm 8.5$ & $68.5 \pm 7.1$ \\
\hline APACHE II score & $19.3 \pm 4.3$ & $21.2 \pm 4.1$ & $22.2 \pm 4.5$ & $21.7 \pm 6.2$ \\
\hline SOFA score & $11.8 \pm 3.0$ & $11.3 \pm 3.3$ & $11.1 \pm 3.0$ & $11.7 \pm 4.0$ \\
\hline BUN (mmol/l) & $33.0 \pm 58.8$ & $9.2 \pm 4.4$ & $32.4 \pm 56.0$ & $10.9 \pm 4.9$ \\
\hline $\mathrm{Cr}(\mu \mathrm{mol} / \mathrm{l})$ & $141.7 \pm 46.5$ & $102.2 \pm 48.2$ & $204.8 \pm 226.8$ & $142.8 \pm 124.9$ \\
\hline $\mathrm{CL}_{\mathrm{Cr}}(\mathrm{ml} / \mathrm{min})$ & $52.6 \pm 26.3$ & $72.2 \pm 33.9$ & $62.1 \pm 69.8$ & $61.2 \pm 33.5$ \\
\hline $\operatorname{ALB}(g / l)$ & $27.1 \pm 3.4$ & $29.3 \pm 5.0$ & $28.5 \pm 4.2$ & $28.7 \pm 4.7$ \\
\hline $\operatorname{ALT}(\mathrm{IU} / \mathrm{l})$ & $538.4 \pm 851.1$ & $20.3 \pm 17.5$ & $536.6 \pm 809.0$ & $36.6 \pm 32.2$ \\
\hline AST (IU/l) & $937.8 \pm 1332.0$ & $23.3 \pm 9.5$ & $891.3 \pm 1264.2$ & $52.7 \pm 61.4$ \\
\hline $\mathrm{TB}(\mu \mathrm{mol} / \mathrm{l})$ & $20.4 \pm 12.3$ & $11.1 \pm 2.1$ & $21.8 \pm 11.5$ & $16.4 \pm 7.9$ \\
\hline WBC $\left(10^{9} / \mathrm{l}\right)$ & $14.9 \pm 3.1$ & $13.5 \pm 5.9$ & $12.5 \pm 5.2$ & $12.8 \pm 5.2$ \\
\hline CRP (mg/l) & $109.2 \pm 77.7$ & $141.1 \pm 91.6$ & $70.9 \pm 59.4$ & $142.7 \pm 86.2$ \\
\hline PCT (ng/ml) & $8.3 \pm 10.0$ & $1.7 \pm 2.2$ & $4.4 \pm 5.0$ & $6.0 \pm 9.5$ \\
\hline \multicolumn{5}{|l|}{ Infection site, $n(\%)^{*}$} \\
\hline Pulmonary & $5(55.5)$ & $6(100.0)$ & $8(80.0)$ & $9(90.0)$ \\
\hline Abdominal & $4(44.4)$ & $0(0)$ & $2(20.0)$ & $1(10.0)$ \\
\hline Blood stream & $0(0)$ & $0(0)$ & $1(10.0)$ & $0(0)$ \\
\hline Others & $1(11.1)$ & $0(0)$ & $1(10.0)$ & $1(10.0)$ \\
\hline
\end{tabular}

Data were expressed as mean $\pm \mathrm{SD}$, or number (percentage)

$A P A C H E$ acute physiology and chronic health evaluation, $B U N$ blood urea nitrogen, $C r$ creatinine, $C L c r$ creatinine clearance, $A L B$ albumin, $A L T$ alanine aminotranferease, $A S T$ aspartate aminotransferase, $T B$ total bilirubin, $W B C$ white blood cell count, $C R P$ C-reactive protein, $P C T$ procalcitonin

${ }^{*}$ Several patients had combined infection sites

\section{RESULTS}

A total of 94 patients were screened. Finally, 35 patients were enrolled in the present study, with a mean (SD) age of $64.3 \pm 12.1$ years (range 31-82 years old) and a mean (SD) body weight of $68.9 \pm 8.1 \mathrm{~kg}$ (range $55-80 \mathrm{~kg}$ ) (Fig. 1). The majority of these patients were male $(82.9 \%)$.
The microorganisms identified in the culture mainly included Acinetobacter baumannnii, Klebsiella pneumonia subsp. pneumoniae, and Pseudomonas aeruginosa (Table 2). The results of microorganisms were all from respiratory isolates although we collected isolates respectively from the respiratory tract, blood, drainage and cerebrospinal fluid. 
Table 2 Organisms identified on culture

\begin{tabular}{|c|c|c|c|c|}
\hline \multirow[t]{2}{*}{ Pathogens* } & \multicolumn{2}{|l|}{ Two step } & \multicolumn{2}{|l|}{ Extended } \\
\hline & $0.5 \mathrm{~g} q 6 \mathrm{~b}(n=9)$ & $1.0 \mathrm{~g} q 8 b(n=6)$ & $0.5 \mathrm{~g} q 6 b(n=10)$ & $1.0 \mathrm{~g} q 8 b(n=10)$ \\
\hline Total number of microorganisms & 6 & 4 & 5 & 12 \\
\hline Acinetobacter baumannii & $3(50.0)$ & $1(25.0)$ & $4(80.0)$ & $4(33.3)$ \\
\hline $\begin{array}{c}\text { Klebsiella pneumoniae } \\
\text { subsp.pneumoniae }\end{array}$ & $1(16.7)$ & $2(50.0)$ & $1(20.0)$ & $3(25.0)$ \\
\hline Pseudomonas aeruginosa & $1(16.7)$ & $1(25.0)$ & / & $3(25.0)$ \\
\hline Proteus mirabilis & $1(16.7)$ & / & / & \\
\hline Enterobacter cloacae & / & / & / & $1(8.3)$ \\
\hline Enterobacter aerogenes & / & / & / & $1(8.3)$ \\
\hline
\end{tabular}

${ }^{*}$ Several patients had combined pathogens

When imipenem was applied in the two-step method, the $T_{\max }$ was significantly shortened compared with the corresponding extended groups ( $0.5 \mathrm{~g} q 6 \mathrm{~h}: 1.5 \pm 0.8$ vs. $2.0 \pm 0.0 \mathrm{~h}$, $p<0.05 ; 1.0 \mathrm{~g} q 8 \mathrm{~h}: 1.0 \pm 0.6$ vs. $2.0 \pm 0.0 \mathrm{~h}$, $p<0.05)$. Furthermore, the $C_{\max }$ was significantly greater in groups with a dose of $1.0 \mathrm{~g} q 8 \mathrm{~h}$ compared with that of $0.5 \mathrm{~g} q 6 \mathrm{~h}$, irrespective of the infusion method (two-step groups: $24.9 \pm 4.9$ vs. $\quad 11.9 \pm 3.9 \mu \mathrm{g} / \mathrm{ml}, \quad p<0.05$; extended groups: $24.9 \pm 4.0$ vs. $12.5 \pm 5.1 \mu \mathrm{g} /$ ml, $p<0.05)$. Similarly, the $\mathrm{AUC}_{0-t}$ and $\mathrm{AUC}_{0-\text { tau }}$ were significantly higher in groups with a dose of $1.0 \mathrm{~g} q 8 \mathrm{~h}$. However, there was no significant difference among the four groups in terms of $T_{1 / 2}, \mathrm{Cl}$ and $\mathrm{Vd}$ (Fig. 2, Table 3). In

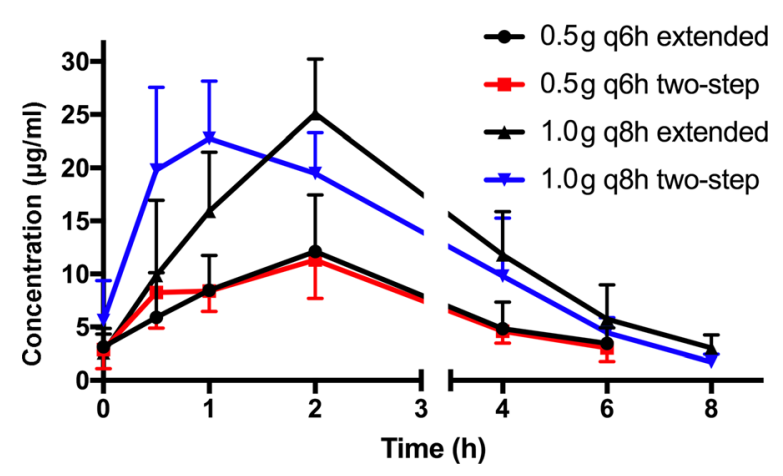

Fig. 2 Concentration-time profile of each regimen in patients with sepsis and septic shock. All values are presented as mean $\pm \mathrm{SD}$ addition, comparisons of PK data between patients with positive and negative microbiology showed that there was roughly no significant difference in PK data between the two groups except that CL in the two-step group $(0.5 \mathrm{~g} q 6 h)$ differed possibly because of the limited sample size (Supplemental Table 1).

For pathogens with an MIC of $0.5,1.0,2.0$ or $4.0 \mu \mathrm{g} / \mathrm{ml}$, all four groups achieved $40 \% T>$ MIC. However, when MIC was $8 \mu \mathrm{g} / \mathrm{ml}$, a higher dose of $1.0 \mathrm{~g} q 8 \mathrm{~h}$ regimen achieved $40 \% \mathrm{~T}>$ MIC, regardless of the infusion, in both the twostep and extended mode. For pathogens with an MIC of $16 \mu \mathrm{g} / \mathrm{ml}$, none of the four groups reached 40\% $T>$ MIC (Table 4).

\section{DISCUSSION}

To our knowledge, the present study is the first to investigate the PK/PD differences between the two-step and extended regimens of imipenem in patients with sepsis and septic shock. The present findings revealed that both regimens similarly achieved targets of $40 \% T>$ MIC. This further implies that an easier extended infusion mode, instead of two-step infusion, may be the optimal administration method of imipenem for the treatment of sepsis and septic shock. 
Table 3 Comparisons of PK parameters of different regimens

\begin{tabular}{|c|c|c|c|c|c|}
\hline Parameters & $\begin{array}{l}\text { Two step }(0.5 \mathrm{~g} \\
q 6 h)\end{array}$ & $\begin{array}{l}\text { Extended }(0.5 \mathrm{~g} \\
q 6 h)\end{array}$ & $\begin{array}{l}\text { Two step }(1.0 \mathrm{~g} \\
q 8 b)\end{array}$ & $\begin{array}{l}\text { Extended }(1.0 \mathrm{~g} \\
q 8 b)\end{array}$ & $p$ value \\
\hline$C_{\max }(\mu \mathrm{g} / \mathrm{ml})$ & $11.9 \pm 3.9^{\mathrm{a}}$ & $12.5 \pm 5.1^{\mathrm{b}}$ & $24.9 \pm 4.9$ & $24.9 \pm 4.0$ & 0.000 \\
\hline$T_{\max }(\mathrm{h})$ & $1.5 \pm 0.8^{\mathrm{c}}$ & $2.0 \pm 0.0$ & $1.0 \pm 0.6^{\mathrm{d}}$ & $2.0 \pm 0.0$ & 0.000 \\
\hline$T_{1 / 2}(\mathrm{~h})$ & $1.9 \pm 0.5$ & $2.1 \pm 0.8$ & $1.8 \pm 0.6$ & $1.7 \pm 0.6$ & 0.565 \\
\hline CL $(1 / h)$ & $10.9 \pm 2.6$ & $10.9 \pm 2.8$ & $11.2 \pm 1.4$ & $10.5 \pm 1.8$ & 0.975 \\
\hline $\mathrm{Vd}(\mathrm{l})$ & $28.7 \pm 8.9$ & $33.0 \pm 16.5$ & $28.0 \pm 7.9$ & $25.1 \pm 7.6$ & 0.480 \\
\hline $\mathrm{AUC}_{0-t}(\mu \mathrm{g} \mathrm{h} / \mathrm{ml})$ & $50.1 \pm 20.9^{\mathrm{e}}$ & $38.0 \pm 15.4^{\mathrm{e}}$ & $83.4 \pm 7.5$ & $85.9 \pm 14.3$ & 0.000 \\
\hline $\begin{array}{l}\mathrm{AUC}_{0-\operatorname{tau}}(\mu \mathrm{g} \mathrm{h} / \\
\mathrm{ml})\end{array}$ & $44.7 \pm 10.5^{\mathrm{e}}$ & $41.0 \pm 11.1^{\mathrm{e}}$ & $91.0 \pm 11.2$ & $97.7 \pm 16.4$ & 0.000 \\
\hline
\end{tabular}

$C_{\max }$ peak concentration, $T_{\max }$ peak time, $T_{1 / 2}$ elimination of half-life, $C L$ imipenem clearance, $V d$ apparent distribution volume, $A U C_{O-t}$ area under the concentration-time curve, $A U C_{O-t a u}$ area under the concentration from zero to the end of the dosing period

a $p<0.05$ compared with two-step infusion $(1.0 \mathrm{~g} q 8 h)$

b $p<0.05$ compared with extended infusion $(1.0 \mathrm{~g} q 8 h)$

c $p<0.05$ compared with extended infusion $(0.5 \mathrm{~g} q 6 h)$

d $p<0.05$ compared with two-step infusion (0.5 g q6h)

e $p<0.05$ compared with extended or two-step infusion $(1.0 \mathrm{~g} q 8 h)$

Table 4 Probability of meeting $40 \% T>$ MIC in patients with sepsis and septic shock receiving imipenem

\begin{tabular}{|c|c|c|c|c|}
\hline \multirow[t]{2}{*}{$\operatorname{MIC}(\mu \mathrm{g} / \mathrm{ml})$} & \multicolumn{2}{|l|}{$0.5 \mathrm{~g} q 6 \mathrm{~b}$} & \multicolumn{2}{|l|}{$1.0 \mathrm{~g} q 8 b$} \\
\hline & Two-step $(n=9)$ & Extended $(n=10)$ & Two-step $(n=6)$ & Extended $(n=10)$ \\
\hline 0.5 & 100 & 100 & 100 & 100 \\
\hline 1 & 100 & 100 & 100 & 100 \\
\hline 2 & 100 & 100 & 100 & 100 \\
\hline 4 & 89 & 80 & 100 & 100 \\
\hline 8 & 11 & 30 & 100 & 80 \\
\hline 16 & 0 & 10 & 0 & 0 \\
\hline
\end{tabular}

$M I C$ minimum inhibitory concentration

The percentage of patients achieving 40\% $T>$ MIC was comparable to the extended mode in the treatment of sepsis and septic shock. Within the MIC range of $0.5-16.0 \mu \mathrm{g} / \mathrm{ml}$, it was found that these two administration regimens did not significantly differ with regard to the target achievement of $40 \% T>$ MIC, although $T_{\max }$ was shorter when imipenem was given in a two-step manner. This result was partly in line with that observed in studies on meropenem. A previous in vitro study revealed that the PTA of the two-step infusion of meropenem completed within $2 \mathrm{~h}$ was not apparently superior to those with a prolonged 2-h infusion. However, the difference on PTA increased when infusion time was prolonged to $4-6 \mathrm{~h}$ [15]. Notably, this study 
was based on the in vitro pharmacodynamics model, which only targeted Pseudomonas aeruginosa, while the present study was a real-world exploratory study conducted in critical patients with various pathogens. In addition, an infusion that lasted no longer than $2 \mathrm{~h}$ was designed in the present study because of the consideration of stability and clinical feasibility. Therefore, comments on the efficacy of the two-step infusion regimen fulfilled in a longer duration could not be made.

Altered PK/PD patterns have been found with a carbapenem antibiotic used under different disease conditions, resulting in insufficient blood drug concentrations. Previous studies have demonstrated that the total CL and $\mathrm{Vd}$ of imipenem markedly fluctuated in critically ill patients compared with normal volunteer populations [19]. For patients with severe sepsis and septic shock, the values of both $\mathrm{Vd}$ and CL of imipenem in the present study appeared to be higher than those observed in healthy volunteers, but these were similar to those in patients with ventilator-associated pneumonia $[19,20]$. The explanation for the pharmacokinetic alteration is that pathophysical changes during septic conditions compromise the absorption, distribution, metabolism and excretion of drugs. On one hand, decreased cardiac output and microcirculation shield the microcirculatory distribution of drugs. On the other hand, the increase in capillary permeability and interstitial edema may enhance drug distribution. Furthermore, the underlying impaired hepatic and renal function also affect the metabolism and clearance of drugs [21].

A high-dose regimen is required for the effective elimination of pathogens less susceptible to imipenem. In the present study, the percentage of cases achieving targets of $40 \%$ $T>$ MIC was nearly $100 \%$ at an MIC of $1-4 \mu \mathrm{g} /$ $\mathrm{ml}$, regardless of whether imipenem was administered with $0.5 \mathrm{~g} q 6 \mathrm{~h}$ or $1.0 \mathrm{~g} q 8 \mathrm{~h}$. However, when MIC was increased to $8 \mu \mathrm{g} / \mathrm{ml}$, the percentage of patients reaching $40 \% T>$ MIC was only $11-30 \%$ at a dose of $0.5 \mathrm{~g} q 6 \mathrm{~h}$ and $80-100 \%$ at a dose of $1.0 \mathrm{~g} q 8 \mathrm{~h}$. Previous studies on pneumonia have reported a high PTA (40\% $T>$ MIC) at an MIC of $1-2 \mu \mathrm{g} / \mathrm{ml}$ when imipenem was used at a dose of $1.0 \mathrm{~g} q 8 \mathrm{~h}$ or $0.5 \mathrm{~g} q 6 \mathrm{~h}$
$[20,22]$. However, imipenem at $1.0 \mathrm{~g} q 8 \mathrm{~h}$ or $1.0 \mathrm{~g} q 6 \mathrm{~h}$ was required for pathogens with a higher MIC in critically ill patients [23]. It is thereby recommended that a maximum imipenem dose of $1.0 \mathrm{~g} q 6 \mathrm{~h}$ should be considered for treating less susceptible pathogens in patients with sepsis and septic shock. However, further large-scale studies are still needed to confirm this statement. In addition, susceptibility in different pathogenic species should be considered. In the present study, almost all regimens achieved $40 \% T>$ MIC against Klebsiella spp. and Escherichia coli, while only a small proportion of imipenem therapies achieved targets against Pseudomonas aeruginosa and Acinetobacter spp., because most of the isolates from the present study revealed that MIC was higher than the resistant breakpoints (data not shown).

There were a few limitations to the present study. First, the sample size was relatively small, and further large clinical studies are warranted to confirm these results. Second, the study was not double-dummy for blind randomization, which may have produced biased results. Third, sepsis and septic shock are actually a disease syndrome that refers to a variety of underlying diseases and pathogens. Furthermore, patient heterogeneity may have affected the results. Fourth, the clinical efficacy of both regimens was not compared because the ultimate outcome would be affected by multiple factors other than antibiotics. Fifth, although previous studies have demonstrated that $40 \% T>$ MIC is associated with the optimal activity for imipenem, recent studies have suggested that a target of $100 \% T>$ MIC might be more appropriate for critically ill patients with severe sepsis [24]. However, the issue of whether the two-step infusion mode is better than the extended infusion mode has been well validated, even when $40 \% T>$ MIC was applied as the target of the present study. Finally, we did not analyze the infection outcome because the aim of this study was to explore the pharmacokinetics of imipenem and we speculate that the infection outcome would be affected by multiple confounding factors during a longer observation period. The comparison of PK data between patients with positive and negative microbiology was performed, and the results are shown in 
Supplemental Table 1, which revealed that there were no significant differences in PK data between the two groups except that CL in the two step ( $0.5 \mathrm{~g} q 6 h)$ differed slightly, possibly because of the limited sample size. It is also noticeable that analysis was infeasible in the other two groups because of the limited sample size. We plan to further study the PK data for patients with positive and negative microbiology in the future with a larger sample size.

\section{CONCLUSIONS}

In conclusion, it was found that both the twostep and extended regimens were comparable to the PK/PD target. For an MIC of eight MIC of $1-2 \mu \mathrm{g} / \mathrm{ml} \mathrm{g} / \mathrm{ml}$, a higher dose (1.0 g q8h) of imipenem should be considered.

\section{ACKNOWLEDGEMENTS}

Funding. No funding or sponsorship was received for this study or publication of this article. The Rapid Service Fee was funded by the authors.

Medical Writing and Editorial Assistance. The medical writing and editorial assistance was funded by MSD China, and provided by Dr. Qian at Medjaden Bioscience Limited.

Authorship. All named authors meet the International Committee of Medical Journal Editors (ICMJE) criteria for authorship for this article, take responsibility for the integrity of the work as a whole, and have given their approval for this version to be published.

Author Contributions. This study was designed, conducted and analyzed by the authors.

Disclosures. Yingzi Huang, Kang $\mathrm{Xu}$, Ying Zhan, Xian Zha, Songqiao Liu, Jianfeng Xie, Lin Liu, Qing Li, Hua Shao and Yi Yang declare that they have no conflict of interest.
Compliance with Ethics Guidelines. The study was approved by the Ethics Committee of Zhongda Hospital. All procedures performed in studies involving human participants were in accordance with the ethical standards of the institutional and national research committee, and with the 1964 Helsinki Declaration, and its later amendments, or comparable ethical standards. Furthermore, the study was in compliance with the American Clinical Trials Register (ClinicalTrials.gov) agreement (registration no. NCT02616354). Written informed consent was obtained from each patient included in the study or legal guardians.

Data Availability. The datasets generated during and/or analyzed during the current study are available from the corresponding author on reasonable request.

\section{REFERENCES}

1. Donnelly JP, Safford MM, Shapiro NI, Baddley JW, Wang HE. Application of the Third International Consensus Definitions for Sepsis (Sepsis-3) Classification: a retrospective population-based cohort study. Lancet Infect Dis. 2017;17:661-70.

2. Herran-Monge R, Muriel-Bombin A, Garcia-Garcia $\mathrm{MM}$, et al. Epidemiology and changes in mortality of sepsis after the implementation of surviving sepsis campaign guidelines. J Intensive Care Med. 2017;34:740-50.

3. Rhodes A, Evans LE, Alhazzani W, et al. Surviving sepsis campaign: international guidelines for management of sepsis and septic shock: 2016. Intensive Care Med. 2017;43:304-77.

4. Rello J, Valenzuela-Sanchez F, Ruiz-Rodriguez M, Moyano S. Sepsis: a review of advances in management. Adv Ther. 2017;34:2393-411.

5. van Hasselt JG, Rizk ML, Lala M, et al. Pooled population pharmacokinetic model of imipenem in plasma and the lung epithelial lining fluid. Br J Clin Pharmacol. 2016;81:1113-23.

6. Craig WA. Interrelationship between pharmacokinetics and pharmacodynamics in determining dosage regimens for broad-spectrum cephalosporins. Diagn Microbiol Infect Dis. 1995;22:89-96. 
7. Vogelman B, Gudmundsson S, Leggett J, Turnidge J, Ebert S, Craig WA. Correlation of antimicrobial pharmacokinetic parameters with therapeutic efficacy in an animal model. J Infect Dis. 1988;158: 831-47.

8. Sinnollareddy MG, Roberts MS, Lipman J, Roberts JA. Beta-lactam pharmacokinetics and pharmacodynamics in critically ill patients and strategies for dose optimization: a structured review. Clin Exp Pharmacol Physiol. 2012;39:489-96.

9. Ahmed N, Jen SP, Altshuler D, Papadopoulos J, Pham VP, Dubrovskaya Y. Evaluation of meropenem extended versus intermittent infusion dosing protocol in critically ill patients. J Intensive Care Med. 2018. https://doi.org/10.1177/ 0885066618784264 .

10. Krueger WA, Bulitta J, Kinzig-Schippers M, et al. Evaluation by monte carlo simulation of the pharmacokinetics of two doses of meropenem administered intermittently or as a continuous infusion in healthy volunteers. Antimicrob Agents Chemother. 2005;49:1881-9.

11. Lorente L, Lorenzo L, Martin MM, Jimenez A, Mora ML. Meropenem by continuous versus intermittent infusion in ventilator-associated pneumonia due to gram-negative bacilli. Ann Pharmacother. 2006;40: 219-23.

12. Viaene E, Chanteux H, Servais H, Mingeot-Leclercq MP, Tulkens PM. Comparative stability studies of antipseudomonal beta-lactams for potential administration through portable elastomeric pumps (home therapy for cystic fibrosis patients) and motor-operated syringes (intensive care units). Antimicrob Agents Chemother. 2002;46:2327-32.

13. Jaruratanasirikul S, Sriwiriyajan S, Punyo J. Comparison of the pharmacodynamics of meropenem in patients with ventilator-associated pneumonia following administration by 3-hour infusion or bolus injection. Antimicrob Agents Chemother. 2005;49:1337-9.

14. Lee LS, Kinzig-Schippers $M$, Nafziger $A N$, et al. Comparison of 30-min and 3-h infusion regimens for imipenem/cilastatin and for meropenem evaluated by Monte Carlo simulation. Diagn Microbiol Infect Dis. 2010;68:251-8.

15. Eguchi K, Kanazawa K, Shimizudani T, Kanemitsu K, Kaku M. Experimental verification of the efficacy of optimized two-step infusion therapy with meropenem using an in vitro pharmacodynamic model and Monte Carlo simulation. J Infect Chemother. 2010;16:1-9.
16. Garcia-Capdevila L, Lopez-Calull C, Arroyo C, Moral MA, Mangues MA, Bonal J. Determination of imipenem in plasma by high-performance liquid chromatography for pharmacokinetic studies in patients. J Chromatogr B Biomed Sci Appl. 1997;692:127-32.

17. Dailly E, Bouquie R, Deslandes G, Jolliet P, Le Floch R. A liquid chromatography assay for a quantification of doripenem, ertapenem, imipenem, meropenem concentrations in human plasma: application to a clinical pharmacokinetic study. J Chromatogr B Analyt Technol Biomed Life Sci. 2011;879:1137-42.

18. Lewis SJ, Kays MB, Mueller BA. Use of Monte Carlo simulations to determine optimal carbapenem dosing in critically ill patients receiving prolonged intermittent renal replacement therapy. J Clin Pharmacol. 2016;56:1277-87.

19. Drusano GL, Plaisance KI, Forrest A, et al. Steadystate pharmacokinetics of imipenem in febrile neutropenic cancer patients. Antimicrob Agents Chemother. 1987;31:1420-2.

20. Sakka SG, Glauner AK, Bulitta JB, et al. Population pharmacokinetics and pharmacodynamics of continuous versus short-term infusion of imipenemcilastatin in critically ill patients in a randomized, controlled trial. Antimicrob Agents Chemother. 2007;51:3304-10.

21. De Paepe P, Belpaire FM, Buylaert WA. Pharmacokinetic and pharmacodynamic considerations when treating patients with sepsis and septic shock. Clin Pharmacokinet. 2002;41:1135-51.

22. Lips M, Siller M, Strojil J, Urbanek K, Balik M, Suchankova H. Pharmacokinetics of imipenem in critically ill patients during empirical treatment of nosocomial pneumonia: a comparison of $0.5-\mathrm{h}$ and 3-h infusions. Int J Antimicrob Agents. 2014;44: 358-62.

23. Couffignal C, Pajot O, Laouenan C, et al. Population pharmacokinetics of imipenem in critically ill patients with suspected ventilator-associated pneumonia and evaluation of dosage regimens. Br J Clin Pharmacol. 2014;78:1022-34.

24. De Waele JJ, Lipman J, Akova M, et al. Risk factors for target non-attainment during empirical treatment with beta-lactam antibiotics in critically ill patients. Intensive Care Med. 2014;40:1340-51. 